\title{
(6) OPEN ACCESS \\ Withdrawing artificial nutrition and hydration from minimally conscious and vegetative patients: family perspectives
}

\author{
Celia Kitzinger, ${ }^{1}$ Jenny Kitzinger ${ }^{2}$
}

${ }^{1}$ Chronic Disorders of Consciousness Research Centre, Department of Sociology, University of York, York, UK

${ }^{2}$ Chronic Disorders of Consciousness Research Centre, School of Journalism, Media and Cultural Studies, Cardiff University, Cardiff, UK

\section{Correspondence to} Professor Celia Kitzinger, Chronic Disorders of Consciousness Research Centre, Department of Sociology, University of York, Heslington, York YO10 5DD, UK;

celia.kitzinger@york.ac.uk

Received 26 August 2013 Revised 1 October 2013

Accepted 5 November 2013

Published Online First

15 January 2014
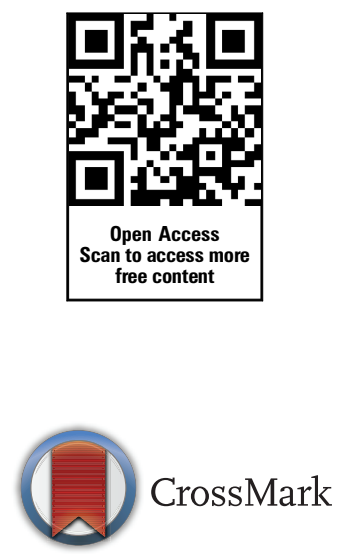

To cite: Kitzinger $C$ Kitzinger J. J Med Ethics 2015:41:157-160

\begin{abstract}
In $W \vee M$, family members made an application to the Court of Protection for withdrawal of artificial nutrition and hydration from a minimally conscious patient. Subsequent scholarly discussion has centred around the ethical adequacy of the judge's decision not to authorise withdrawal. This article brings a different perspective by drawing on interviews with 51 individuals with a relative who is (or was) in a vegetative or minimally conscious state (MCS). Most professional medical ethicists have treated the issue as one of life versus death; by contrast, families - including those who believed that their relative would not have wanted to be kept alive- focused on the manner of the proposed death and were often horrified at the idea of causing death by 'starvation and dehydration'. The practical consequence of this can be that people in permanent vegetative state (PVS) and MCS are being administered life-prolonging treatments long after their families have come to believe that the patient would rather be dead. We suggest that medical ethicists concerned about the rights of people in PVS/ MCS need to take this empirical data into account in seeking to apply ethical theories to medico-legal realities.
\end{abstract}

In the English Court of Protection case, $W v M,{ }^{1}$ the family of a woman in a minimally conscious state (MCS) applied for authorisation for artificial nutrition and hydration (ANH) to be withdrawn with the inevitable result that the patient would die. As has been widely noted, this is the first such case in the English courts concerning someone diagnosed as being in a MCS as opposed to a permanent vegetative state (PVS) and - unlike PVS cases before and sincethe application was refused. Another distinctive feature, less commented upon, is that unlike previous cases concerning PVS patients in the UK, from Bland $^{2}$ onwards, the application for withdrawal in W $v M$ was made by the patient's family rather than by a NHS Trust (since the Trust concerned did not believe that withdrawal of ANH was in the patient's best interests). The extensive commentary that this case has already attracted is concerned with the extent to which the judgement engaged adequately with the 'best interests', precedent autonomy, quality of life and human rights of the patient (known only as $\mathrm{M}$ ). Many articles focus on philosophical arguments for why ANH should have been withdrawn-for example, on the grounds that keeping the patient alive was "incompatible with the legal requirement to respect the past wishes of incompetent people", because the burdens of ANH outweigh the benefits for people in $\mathrm{MCS}^{4} 5$ and because of distributive justice considerations. ${ }^{6}$ Such arguments extend beyond the facts of the particular case and articulate principles that potentially apply to MCS (and sometimes PVS) patients more generally. In this article, we extend these philosophical discussions further by bringing them into dialogue with empirical data: our interview-based study of the experience, and ethical deliberations, of families who have a relative in a vegetative state (VS) or MCS.

Following Bland, ANH withdrawal from PVS patients must be authorised by the courts-and, under English law (in contrast to the USA), relatives do not have a deciding voice on this (or any other) treatment decision for an incapacitated adult family member. When family views are reported in cases brought by the Trusts, they are virtually always supportive of ANH withdrawal, with little evidence of dissent. (See $\operatorname{Re} G^{7}$ for an exception.) In Bland, ${ }^{2}$ the patient's father is quoted as saying: "He certainly wouldn't want to be left like he is. I would feel that he should be removed [from ANH] and the family feel the same"; in NHS Trust $v J,{ }^{8}$ the patient's husband says: "she would not wish her life to be prolonged in her present condition. I believe [...] she would wish artificial hydration and nutrition to be withdrawn". Similar views are attributed to the family in many other cases. ${ }^{9}$ This may lead medical ethicists to believe that families are generally supportive of ANH withdrawal for PVS and MCS patients. It is, however, unlikely that the views of these families represent the views of the majority of people with relatives in PVS/MCS, only a tiny percentage of whom are involved in court cases for ANH withdrawal: in the 20 years since Bland, ${ }^{2}$ fewer than 100 such applications have reached the courts.

In sum, $W v M$ (and the PVS withdrawal cases that precede and follow it) is merely the tip of a very large iceberg usually invisible to medical ethicists. The vast majority of people in PVS and MCS and their families are never represented in medical case studies or legal debate. This article explores salient ethical features in some of these families' views about treatment withdrawal. We show how the family represented in $W v M-$ for all its singularity-shares many common features with the experiences of families of PVS and MCS patients across England and Wales, but with the critical distinction that very few of our interviewees, 
including those who believe that their relative would rather have been dead than kept alive in their current condition, are willing to countenance ANH withdrawal, still less make (or support the Trust in making) an application to the Court of Protection. We suggest that medical ethicists concerned about the rights of people in PVS/MCS need to take this empirical data into account in seeking to apply ethical theories to medico-legal realities.

\section{METHOD}

The research reported here is part of a larger in-depth interview study of the experiences of families with a severely brain-injured relative. The research ethics committees at the Universities of York and Cardiff initially approved the study, and we began recruitment of participants as widely as possible starting with our own social contacts and via brain injury support groups. This was made possible in part because the researchers (who are sisters) themselves have a severely brain-injured sister, and said so in the recruitment information: five of the early interviews were with people previously encountered via our personal involvement in the networks connected to brain injury (eg, via support networks in which we participated, events we attended). We also used snowball sampling and contacted people via care homes and contacted some who had spoken publicly about their experience. The study subsequently received NHS approval (from Berkshire Research Ethics Committee, REC reference number: 12/SC/0495), and we were also able to recruit via consultants, although all interviews took place off NHS premises (generally in people's homes). Prospective participants were usually approached via email, and all 51 participants were interviewed by one or other of the two authors, both of whom have extensive experience in interview and focus group research in the field of health and illness, and both of whom teach qualitative methodologies (including interviewing) and have published widely on qualitative research methods. Interviews were mostly one-to-one, but occasionally in pairs (eg, a husband and wife asked to be interviewed together, as did a mother and daughter). We almost always conducted the interviews without other people present: exceptions were one interview at which a young child was present and another which took place in the same room as the PVS daughter of the interviewee (who cared for her at home). Interviewees were mostly parents, siblings, spouses/ partners and adult children of the patient. Most patients were currently either PVS or MCS (some had died by the time of interview; others had emerged from chronic disorders of consciousness with severe neurological deficits). To maximise anonymity, we avoid giving further details.

The interview guide was deliberately wide-ranging to allow people to tell their stories in their own ways, and we did not impose a uniform structure or set of identical questions. During the course of the interviews, we also answered questions about our own experiences as sisters of a severely brain-injured patient when asked, and occasionally volunteered information when it seemed helpful (eg, to show that we understood and could empathise with difficult experiences). The majority of interviews lasted between 2 and 4 h (with breaks), the shortest was $45 \mathrm{~min}$ and the longest was $7 \mathrm{~h}$ (with breaks). Interviewing started in November 2010 and continued throughout and subsequent to the period that $W v M$ received extensive press coverage (in July 2011 and again in September/October 2011). Interviewees occasionally referred spontaneously to the case, and some (including two families with relatives in MCS who had already initiated enquiries about ANH withdrawal) were following it closely. Interviews were transcribed orthographically (with care taken to maximise confidentiality; Saunders B et al, unpublished data) and analysed thematically to identify recurrent patterns (themes). ${ }^{10}$ In this article, we focus on those parts of the interviews where participants discuss whether or not they would consider ANH withdrawal for their relatives-and this was systematically coded by the two authors for the purpose of this paper. After 51 interviews, this was a heavily saturated category (ie, we were repeatedly hearing the same comments from different participants); however, very few of the interviewees (at the time of interview) had witnessed a relative dying from withdrawal of $\mathrm{ANH}-$ and this will be the subject of future work.

\section{FINDINGS}

The family in $W v M$ is not unusual in believing that the patient would have rather been dead than sustained in their current condition: this view was shared by two-thirds of our interviewees. Those who believed the person would have wanted to be kept alive were (with two exceptions, both from the same family) within the first 2 years of the precipitating event. Families generally arrived at the view that the person would rather be dead only after exhausting all the possibilities that their relative could make a recovery to a quality of life that the patient would find acceptable. In the first few years after injury interviewees usually believed it was 'too early to give up', and that the person might 'beat the odds' to make a recovery to some meaningful (to them) quality of life. In some cases, doctors had suggested withdrawing treatment during this earlier period and interviewees resisted this, claiming that their relative had been 'written off' as a 'vegetable' and was being denied rehabilitation opportunities. One interviewee, for example, felt very threatened by clinicians' suggestions that ongoing treatment might be futile and described her alarm that ANH might be withdrawn. She had sought legal advice and been reassured that this could not happen if she disagreed-at least not without long delays, detailed clinical investigation and her views being taken into account. However, she felt she was in a 'battle' to defend her husband and, throughout the interview, discussed her strategies for not giving the clinical team any 'ammunition' that might allow treatment to be withheld/withdrawn. Almost all of the interviewees who now believed that the person had suffered 'a fate worse than death' had previously 'consented' to, or even fought for, life-sustaining interventions. Some now regretted this. Opinions then can clearly shift over time with experience and as the prognosis becomes clearer.

M's family was typical in this respect. It was only 'after several years of exploring all options in the hope that she would recover consciousness' (WvM, para 2) that the family (her mother, partner, sister, nephew and mother-in-law) came to the view that $M$ would not want to continue to be kept alive. In outlining the background to the case, Baker J records that:

From an early stage the consensus of medical opinion was that there was no realistic prospect that any improvement could be achieved in M's condition. For some time, the family members, in particular S [M's partner] fought hard to ensure that every possible attempt was made to identify processes of rehabilitation which might bring about some improvement. (para 15)

M's sister, B, describes how S "kept saying we have got to give her every chance”. The judgement summarises S's views:

He was determined that $\mathrm{M}$ was going to get better - I said: "She is all I have got". He said that he felt that they, by which he means the doctors, were giving up on her and he wanted to keep fighting. (para 119) 
It was only 4 years later, with no significant evidence of improvement, that M's family 'gradually came to the view' (para 16) that $\mathrm{M}$ would not want her life artificially sustained.

As we have detailed elsewhere, ${ }^{11}$ by the time families decide that their relative would not wish to have continued lifesustaining treatment, the patient has usually stabilised and the only remaining 'artificial' means of life support is clinically assisted nutrition and hydration. The 'window of opportunity' for allowing death in any other way (eg, by withdrawing ventilation) is closed since the person is no longer dependent on other forms of support.

Rather than actively seek withdrawal of ANH, most families at this point are waiting for a 'natural death'. Interviewees reported that patients now had 'ceilings of care' in place, including 'do not attempt cardiopulmonary resuscitation' (DNACP) and an agreement not to aggressively treat infections (eg, with intravenous antibiotics). These interviewees often drew a distinction between 'going along' with suggestions from clinicians that aggressive interventions were no longer appropriate (allowing 'fate to take its course') and taking 'active' steps. One woman we interviewed spoke about her husband:

I don't feel it's my place, as they are doing at the moment with ' $\mathrm{M}$ ', to go to a court and say 'I want his nutrition withdrawn'. I don't think I could do that. But I don't think it's right or fair to actively take steps to prolong this life. I suppose I'm waiting for Simon to die naturally. (Kate)

Another made a similar point about her daughter:

When you see she is very ill [with pneumonia] you think, "yes, the time has come", you know, and "if this is it, then so be it". In fact it's a sort of relief in a way, isn't it, to know that there is an end to it. [...] I wouldn't do anything actively to change it... But on the other hand, if it finished I think I'd be relieved. (Ann)

Again, M's family is typical in having reached this position: her sister reported that she could not see the point of giving $\mathrm{M}$ antibiotics "to bring her round for years of more suffering for this-I would rather let nature take its course" (para 116) and the family seems to have asked that $\mathrm{M}$ should not be given a flu jab (para 109).

What makes M's family unusual is that they were willing to request $\mathrm{ANH}$ withdrawal. This was considered utterly abhorrent to most of those we interviewed:

I can't imagine that she would ever want to live as she is now. [...] but the [ANH withdrawal] alternative is too cruel. [...] [and] even if they agreed to it, it's too painful, you know. I couldn't do that. [....] You know, we couldn't put her through it. (Ann)

When they told me that I felt like screaming. I thought, 'you are MAD!' I didn't even contemplate it. I just don't understand how anyone can sanction that law' (i.e. the common law established by Bland). (Bob)

I couldn't believe that that [ANH withdrawal] was the method. Everybody I've talked to has said, "there must be better ways than that in this day and age." [...] What a stupid, stupid way of doing it. (Mark)

Failing to feed (or to provide water) to a loved one via whatever route (orally or by tube) - even because of the conviction that they would prefer to be dead-is a highly emotive issue with deep cultural resonance. One interviewee told us that ANH had been withdrawn (without recourse to the courts) from her PVS husband after she had expressed the view that he would rather be dead. She intervened to reverse this decision because she found it so deeply disturbing:
I just couldn't bear that he was starving [...] I just thought, what a horrible- what a dreadful way to live your last days. I just thought it was awful. (Imogen)

She now regrets intervening because her husband's subsequent existence and eventual death (from untreated gangrene) was so terrible she does not think that ANH withdrawal could have been worse:

The gangrene was horrible. Have you ever seen gangrene? It's so horrific. It's like two years earlier he could be starved to death, now he was going to have to die of gangrene. [...] If I go back to that moment where I said "you can't starve him to death", I did regret it sometimes.... (Imogen)

Another interviewee believed she could have tried to enforce her husband's wishes (supported by his legally valid Advance Decision naming her as proxy), but found she couldn't bring herself to try this route at the point at which it became relevant.

I actually got to the stage of not allowing the next [feeding] tube down but I decided I couldn't do that for Christmas. I couldn't have that on my conscience for every fucking Christmas afterwards. (Shula)

Interviewees were often concerned that, even with a confirmed VS diagnosis, it was possible that their relative would experience pain and suffering and there was a widespread perception that lethal injections would be more humane, compassionate and dignified than 'death from neglect' as a result of treatment withdrawal. A brother comments: "There are ways and means of doing it compassionately. I'd rather her be given a lethal injection" (Harry). Other interviewees report:

We all thought [ANH withdrawal] was barbaric. But then being kept alive that way is barbaric [...] I mean it [death following ANH withdrawal] is better than for ever living that way. But really, truthfully, what the hell is this? The system has to be in place where if [surgery and rehabilitation] is a failure, if it hasn't worked, then you can help that person die with dignity. (Rose)

I would view it [a lethal injection] as a kinder decision [...] Because if you stop feeding them, they are going to die. If you've made that decision, you might as well do it as humanely as you possibly can. [...] To starve somebody to death seems a particularly cruel thing to do. (Brendan)

Even when families were told by clinicians that the person would receive palliative care, they still found $\mathrm{ANH}$ withdrawal unacceptable-if not for the patient, then for the rest of the family. One mother says:

We hated it. They reassured us that, you know, "oh he would be sedated, he wouldn't feel any pain." But we would have to sit there for up to three weeks to, basically, watch him die. Craig [patient's brother] said, "but it's so awful Mum-I couldn't bear for them to do that to Charles." [...] There's no way I'd ask for it. No way. (Tania)

Tania adds, "I would rather do it [kill him] myself".

Many interviewees had thought about killing the patient themselves-with varying levels of seriousness. (None had actually done so, but we remove pseudonyms from this section to maximise anonymity as this is highly sensitive data, and something some interviewees had, for obvious reasons, not discussed with clinical teams, and sometimes had not revealed to other members of their families.) One mother referred to another legal case widely covered in the media: that of Francis Inglis, ${ }^{12}$ who killed her vegetative son with a heroin overdose. She said: "everyone who's been in our situation can relate to that". 
She says she could not do it herself but: "I wish I had her courage". Another interviewee, who unusually was considering pursuing ANH withdrawal for her relative, commented: "I wouldn't say that it had never occurred to me that putting a pillow over his face might be a kinder way." A sister told us that after investigating the possibilities of $\mathrm{ANH}$ withdrawal for her MCS brother and discovering it was unlikely to be approved, "I personally wanted to take his life illegally". Although her family dissuaded her from doing so (not wanting to lose another family member), she had reasoned that:

However horrible prison was, however humiliating and frustrating and boring and scary, it would be nothing compared to being trapped within your own body and in pain. So in all the arguments I had with myself, that's what I'd come back to... All my life my thing has been to protect my family. And protecting him and keeping him alive were in conflict. [...] Every day that nothing happened was harming him.

Another interviewee commented:

There was a moment when I contemplated killing her [my mother] [....] And now my worst fear is that, in the strange cocooned world with antibiotics on tap where she lives, she may never die.

In yet another family, an interviewee told us how she planned a mercy killing because she felt she had promised her loved one that he would not have to live in a vegetative state. "I took the thing off his arms a couple of times just to see how loud the alarm was and what happened you know. Because I thought 'I can't do it if he's going to be resuscitated'". She had chosen a hotel near the hospital in which she planned-after making sure she had successfully accomplished the murder-to kill herself undisturbed. It was, however, “a promise I didn't keep". Although, in the end, each of these interviewees had decided that carrying out a 'mercy killing' was not the answer, they were angry that the current system had, they felt, forced them into the position where they were contemplating it, and some felt guilty at their failure to carry through.

In sum, some PVS and MCS patients are being administered life-prolonging treatments long after their families have come to believe that the patient would rather be dead. In the view of these interviewees, this compromises patients' dignity, violates their prior expressed wishes and may also cause them pain and suffering-but as long as an application for ANH withdrawal is the only legal assured exit route that might be available, most families are unlikely to advocate for the patient's death.

\section{CONCLUSION}

$W v M$ is the tip of the iceberg in terms of engaging in ethical concerns about the best interests, precedent autonomy and human rights of PVS/MCS patients. Whereas previous commentary has focused analysis on the judicial reasoning in $W v M$, here we have drawn attention to the fact that this case is exceptional insofar as a family has been willing to seek ANH withdrawal. Our data show that many families are not willing even to consider ANH withdrawal, however convinced they are that the person would rather be dead. Those who had relatives in MCS also usually believed-especially in the wake of $W v M-$ that their application was unlikely to succeed. ${ }^{13}$ Philosophical debate about whether or not ANH should be withdrawn from PVS/MCS patients will contribute most usefully in applied contexts if this lived reality is taken into account, and other ways of bringing about the death of PVS/MCS patients (eg, terminal sedation) are given full ethical consideration.

Acknowledgements We would like to thank all the families who took part in the research, the practitioners who discussed our research with us and the other members of the York-Cardiff Chronic Disorders of Consciousness Research Centre for stimulating discussions about the data. We are grateful to Dr Benjamin Saunders, our research assistant, for anonymising the data and for some initial thematic coding.

Contributors Both CK and JK contributed equally to conception and design, analysis and interpretation of data, drafting the article and revising it critically for important intellectual content. They also approved the version as submitted for publication and are responsible for the overall content as guarantors.

Funding Brocher Foundation (one month writing fellowship for both authors). This work was part-funded by the Wellcome Trust (ref: 097829/Z/11/A).

Competing interests None.

Ethics approval University of York Humanities and Social Sciences Ethics Committee, Cardiff University JOMEC Ethics Committee, NHS Berkshire Research Ethics Committee (REC reference number: 12/SC/0495).

Provenance and peer review Not commissioned; externally peer reviewed.

Data sharing statement Anonymised transcripts of 20 of the interviews have been made available to other members of the York-Cardiff Chronic Disorders of Consciousness Research Centre under conditions of confidentiality.

Open Access This is an Open Access article distributed in accordance with the terms of the Creative Commons Attribution (CC BY 3.0) license, which permits others to distribute, remix, adapt and build upon this work, for commercial use, provided the original work is properly cited. See: http://creativecommons.org/licenses/ by/3.0/

\section{REFERENCES}

1 W v M (2011) EWHC 2443 (Fam).

2 Airedale NHS Trust $v$ Bland [1993] AC 789.

3 Mullock $A$. Best interests and the sanctity of life after $W v M$. J Med Ethics. 2013;39:553-4

4 Gannon W. Burdens of ANH outweigh benefits in the minimally conscious state. J Med Ethics 2013;39:551-2.

5 Jackson $E$. The minimally conscious state and treatment withdrawal: $W v M$. J Med Ethics 2013;39:559-61.

6 Wilkinson D, Savulescu J. Is it better to be minimally conscious than vegetative. J Med Ethics 2013:39(9):557-8.

7 Re G (Persistent Vegetative State) [1995] 2 FCR 46

8 NHS Trust v J [2006] FD06P01318.

9 NHS Trust v T [2002] All ER (D) 125); NHS Trust v I [2003] EWHC 2243 (Fam); Re CW [2010] EWHC 3448 (FAM) (NHS Trust v AW [2013] EWHC 78 (COP).

10 Braun V, Clarke V. Using thematic analysis in psychology. Qualitative Research in Psychology 2006;3(2):77-101.

11 Kitzinger J, Kitzinger C. The 'window of opportunity' for death after severe brain injury: Family experiences. Sociology Health IIIn 2013;35(7):1095-112.

$12 R$ v Inglis [2010] EWCA Crim 2637.

13 Kitzinger C, Kitzinger J. "M", Polly and the right to die. Bioeth Forum (Hastings blog) 10 December 2011. http://www.thehastingscenter.org/Bioethicsforum/Post. aspx?id $=5557 \&$ blogid $=140$ 